\title{
Editorial
}

\section{Financial Networks 2019}

\author{
Benjamin Miranda Tabak $\mathbb{D}^{1},{ }^{1}$ Thiago Christiano Silva $\mathbb{D}^{2,3}$ and Ahmet Sensoy $\mathbb{D}^{4}$ \\ ${ }^{1}$ Fundação Getúlio Vargas, Escola de Políticas Públicas e Governo (FGV/EPPG), Brasilia, Brazil \\ ${ }^{2}$ Universidade Católica de Brasília, Brasília, DF, Brazil \\ ${ }^{3}$ Universidade de São Paulo, Ribeirão Preto, SP, Brazil \\ ${ }^{4}$ Bilkent University, Ankara, Turkey \\ Correspondence should be addressed to Benjamin Miranda Tabak; benjaminm.tabak@gmail.com
}

Received 18 October 2019; Accepted 19 October 2019; Published 5 December 2019

Copyright (C) 2019 Benjamin Miranda Tabak et al. This is an open access article distributed under the Creative Commons Attribution License, which permits unrestricted use, distribution, and reproduction in any medium, provided the original work is properly cited.

This special issue on financial networks seeks to bring novel methods and discussions to improve our understanding of financial markets. The bulk of the literature studies, interbank markets, or stock markets networks. This literature has provided important insights for the development of portfolio and risk management and financial regulation.

Since the global financial crisis of 2008, many important aspects of how networks can amplify shocks have come to the debate in the academia and also for policymaking. For instance, the integration of other contagion transmission channels besides the traditional interbank and stock markets is an important step to take if one wants to really understand how interconnectedness drives loss amplification across different financial systems. Therefore, there are many areas that are at their early stages in terms of modeling and further research is necessary. In this special issue, we seek to fill some gaps in the literature and provide a relevant contribution to the discussion of these issues.

Some papers in our special issue estimate systemic risk (Systemic Risk in the Interbank Market with Overlapping Portfolios) and model contagion using an agent-based modeling approach combined with complex networks (Nonlinear Dynamics Characteristic of Risk Contagion in Financial Market Based on Agent Modeling and Complex Network) and risk investor contagion (Price Linkage Rumors in the Stock Market and Investor Risk Contagion on Bilayer-Coupled Networks).

We have papers that deal with stock price prediction using knowledge graphs (Anticipating Stock Markets of the Renowned Companies: A Knowledge Graph Approach), and also a paper that combines network decomposition with spatial econometrics (Analyzing Stockbrokers' Trading Patterns: A Network Decomposition and Spatial Econometrics Approach).

Some papers deal with stock market networks from a new methodological perspective (Thermodynamic Entropy in Quantum Statistics for Stock Market Networks) with mutual funds (Modeling Overlapped Mutual Funds' Portfolios: A Bipartite Network Approach) and with credit default swaps (Weight of the Default Component of CDS Spreads: Avoiding Procyclicality in Credit Loss Provisioning Framework).

Other papers deal with the effect of investor behavior on returns (Understanding How Short-Termism and a Dynamic Investor Network Affects Investor Returns: An Agent-Based Perspective), pairs-trading strategies (Optimizing the Pairs-Trading Strategy Using Deep Reinforcement Learning with Trading and Stop-Loss Boundaries), control strategies ( $\mathrm{P} \mathrm{D}^{9}$ Control Strategy for a Fractional-Order Chaotic Financial Model), and EC-structure (EC-Structure: Establishing Consumption Structure through Mining E-Commerce Data to Discover Consumption Upgrade).

The set of papers in this issue contributes to enhancing our understanding of financial and complex networks and also to the application of new methods. We highlight the importance of the use of multilayer and multiplex networks to improve the modeling of real-world networks that may have distinct dimensions. We also highlight the relevance of agent-based modeling in providing new insights on 
economic and financial behaviors of both investors' and consumers' financial products or services.

Several areas need further research. Financial networks comprised of commodities are still understudied and could provide important insights (see [1]). Their relationship with stock markets and other financial markets is also an important issue. The integration of new contagion transmission channels $[2,3]$ is also of utmost importance to avoid underestimating the ability of financial networks in amplifying losses. How to model efficiency and performance using information on network formation [4-6] is also an important task, as well as that of using dynamic efficiency tools to model the evolution of financial markets [7].

\section{Conflicts of Interest}

The editors declare that they have no conflicts of interest.

\section{Benjamin Miranda Tabak Thiago Christiano Silva Ahmet Sensoy}

\section{References}

[1] B. M. Tabak, T. R. Serra, and D. O. Cajueiro, "Topological properties of commodities networks," The European Physical Journal B, vol. 74, no. 2, pp. 243-249, 2010.

[2] T. C. Silva, M. A. da Silva, and B. M. Tabak, "Systemic risk in financial systems: a feedback approach," Journal of Economic Behavior \& Organization, vol. 144, pp. 97-120, 2017.

[3] T. C. Silva, M. D. S. Alexandre, and B. M. Tabak, "Bank lending and systemic risk: a financial-real sector network approach with feedback," Journal of Financial Stability, vol. 38, pp. 98$118,2018$.

[4] T. C. Silva, S. M. Guerra, B. M. Tabak, and R. C. C. Miranda, "Financial networks, bank efficiency and risk-taking," Journal of Financial Stability, vol. 25, pp. 247-257, 2016.

[5] T. C. Silva, B. M. Tabak, D. O. Cajueiro, and M. V. B. Dias, "A comparison of DEA and SFA using micro- and macro-level perspectives: efficiency of Chinese local banks," Physica A: Statistical Mechanics and its Applications, vol. 469, pp. 216-223, 2017.

[6] T. C. Silva, B. M. Tabak, D. O. Cajueiro, and M. V. B. Dias, "Adequacy of deterministic and parametric frontiers to analyze the efficiency of Indian commercial banks," Physica A: Statistical Mechanics and its Applications, vol. 506, pp. 1016-1025, 2018.

[7] A. Sensoy and B. M. Tabak, "Dynamic spanning trees in stock market networks: the case of Asia-Pacific," Physica A: Statistical Mechanics and its Applications, vol. 414, pp. 387-402, 2014. 


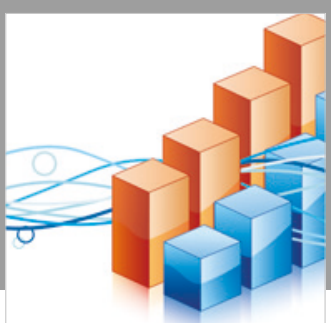

Advances in

Operations Research

\section{-n-m}
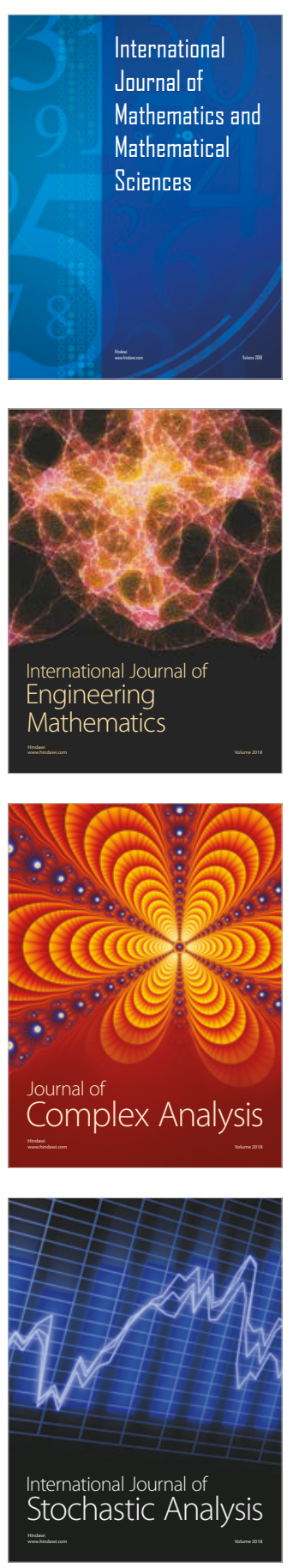
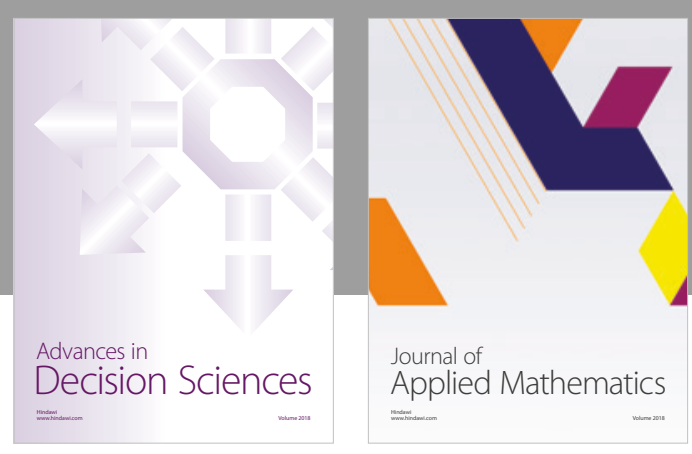

Journal of

Applied Mathematics
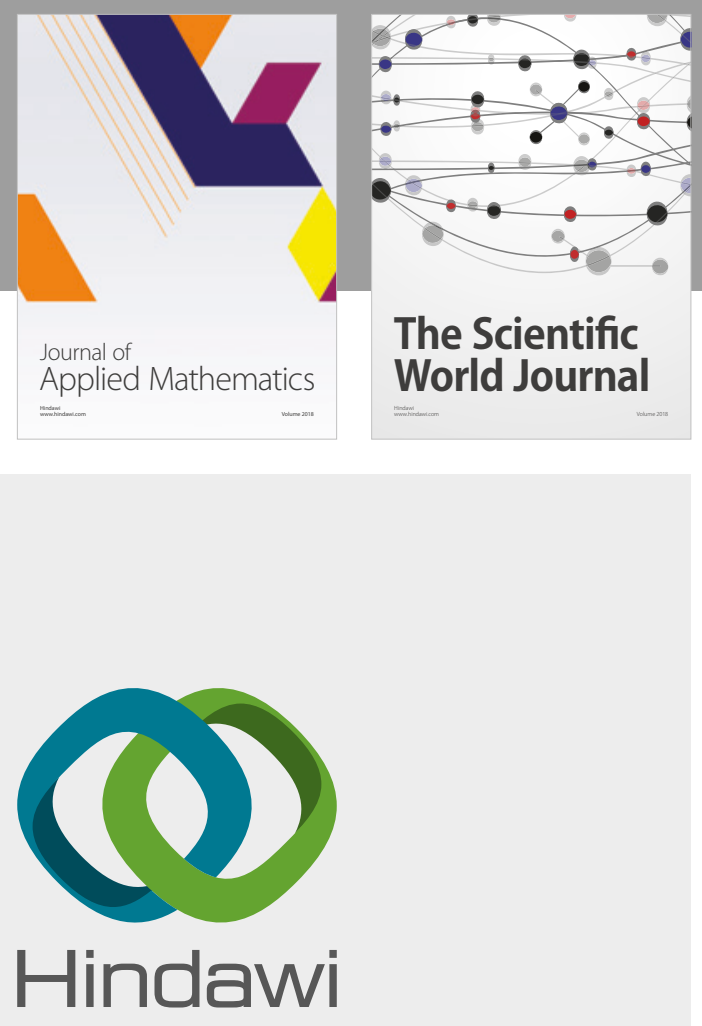

Submit your manuscripts at

www.hindawi.com

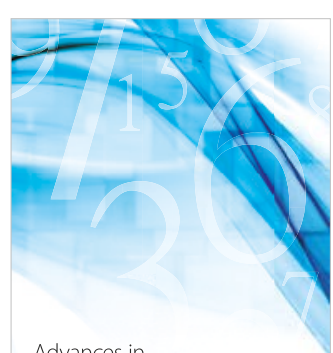

Advances in
Numerical Analysis
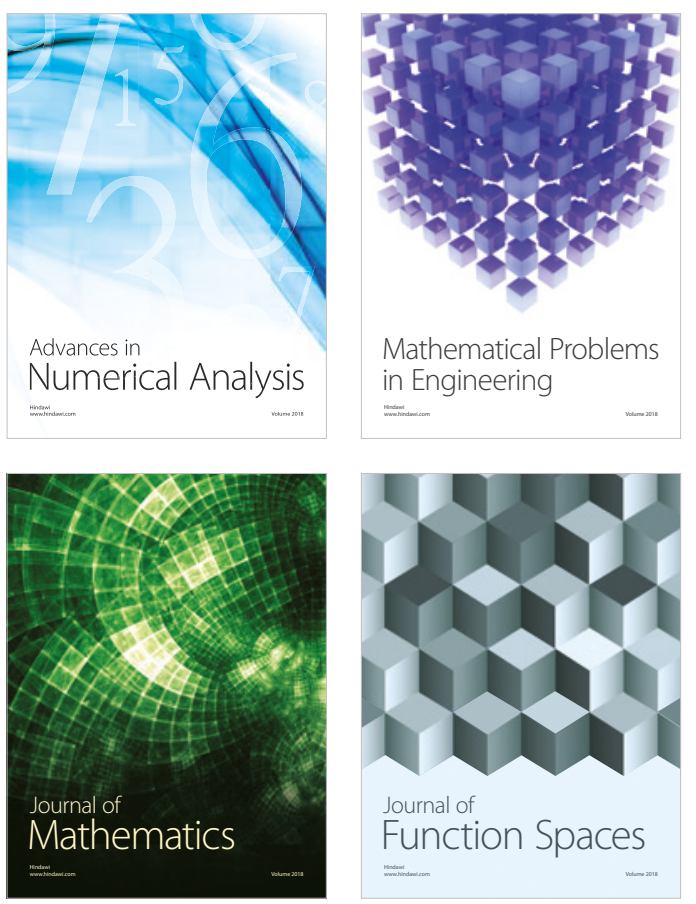

Mathematical Problems in Engineering

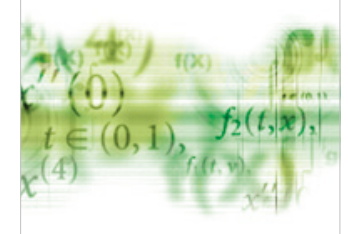

International Journal of

Differential Equations

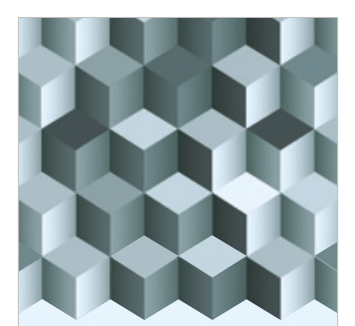

Journal of

Function Spaces
The Scientific

World Journal

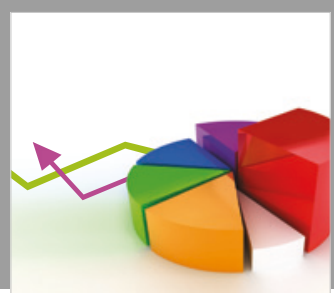

Journal of

Probability and Statistics
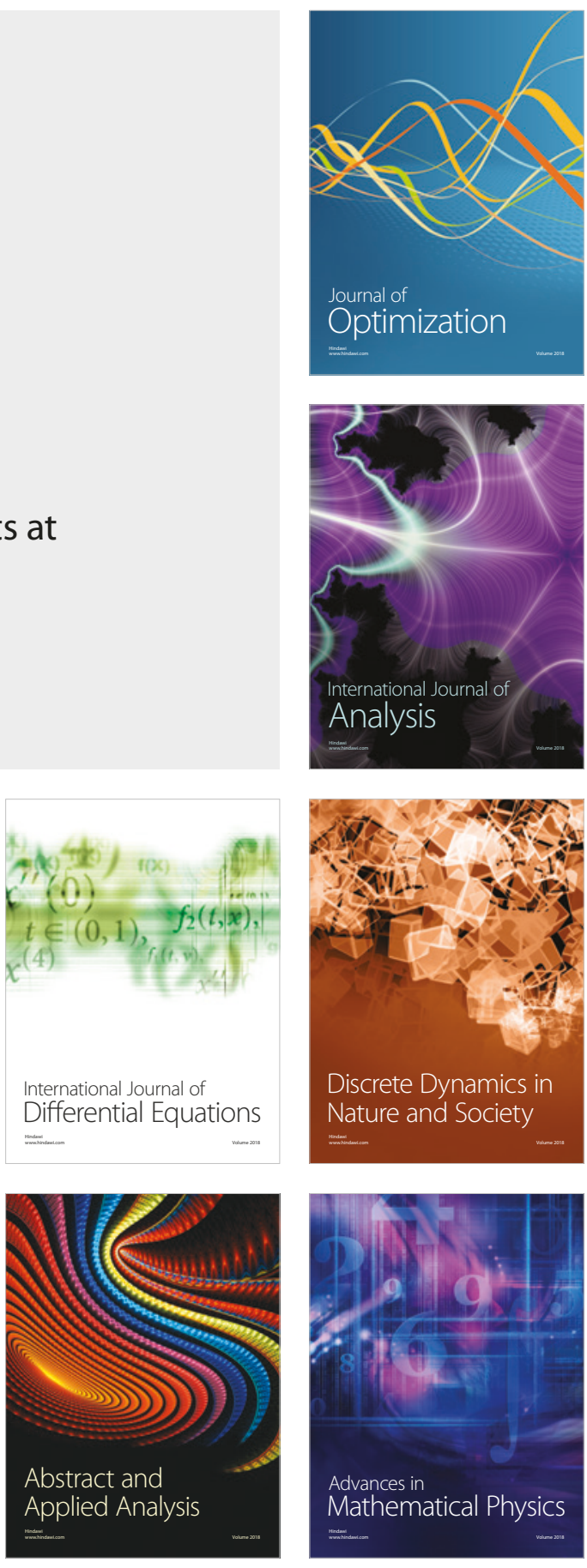